\title{
Review Article \\ Synthesis and Application of Iron Oxide Nanoparticles in Bone Tissue Repair
}

\author{
Da Lu $\mathbb{D}^{1,2,3}$ Xueqing Wu, ${ }^{1,2,3}$ Wei Wang, ${ }^{1,2,3}$ Chenghao Ma, ${ }^{1,2,3}$ Baoqing Pei $\mathbb{D}^{1,2,3}$ \\ and Shuqin $\mathrm{Wu} \mathbb{1}^{4}$ \\ ${ }^{1}$ School of Biological Science and Medical Engineering, Beihang University, Beijing /100191, China \\ ${ }^{2}$ Beijing Key Laboratory for Design and Evaluation Technology of Advanced Implantable \& Interventional Medical Devices, \\ Beihang University, Beijing /100191, China \\ ${ }^{3}$ Beijing Advanced Innovation Center for Biomedical Engineering, Beihang University, Beijing /100191, China \\ ${ }^{4}$ School of Big Data and Information, Shanxi Polytechnic Institute, Shanxi 036000, China
}

Correspondence should be addressed to Baoqing Pei; pbq@buaa.edu.cn and Shuqin Wu; wushuqin@nuc.edu.cn

Received 6 May 2021; Accepted 14 August 2021; Published 16 September 2021

Academic Editor: Domenico Acierno

Copyright (c) $2021 \mathrm{Da}$ Lu et al. This is an open access article distributed under the Creative Commons Attribution License, which permits unrestricted use, distribution, and reproduction in any medium, provided the original work is properly cited.

\begin{abstract}
Nanoparticles play a vital role in bone tissue repair engineering, especially iron oxide nanoparticles (IONPs), which have magnetic properties, semiconductor properties, and nontoxicity at the same time, and their applications in biomedicine have received widespread attention. This review summarizes the excellent performance of IONPs in enhancing scaffold functions, promoting stem cell differentiation, and labeling positioning, in order to understand the research progress and future development trends of IONPs in bone tissue repair engineering, as well as the security issues. Firstly, IONPs can affect the expression of genes and proteins to accelerate the process of biomineralization under a magnetic field. Then, the composite of IONPs and polymers can synthesize a scaffold which can promote the attachment, proliferation, and bone differentiation of stem cells. Furthermore, IONPs can also mark the location of drugs in the body to follow up the process of bone repair. Therefore, extensive research on the manufacturing and application range of IONPs is of great significance to bone tissue repair engineering.
\end{abstract}

\section{Introduction}

As we all know, physical stimulation enhances the bone rebuilding capacity significantly, including stretching, compression, fluid shear stress, and heat $[1,2]$. Additionally, the magnetic stimulation of static magnetic fields (SMFs) and electromagnetic fields (EMFs) also improve the bone rebuilding capacity greatly $[3,4]$. So, the application of MNPs as an intermediate medium has received extensive attention in medical research, such as targeted drug delivery, magnetic resonance imaging (MRI), local tissue hyperthermia, tumor treatment, bioseparation, and biosensing [5], and compared to other materials, MNPs have lower production cost, more stable physical and chemical properties, and better biocompatibility [6].
Magnetic particles are slowly deposited on the surface of the cell membrane under the action of a magnetic field and are endocytosed by the cell. After the magnetic particles enter the cell, it is easier to affect the physiological function of the cell $[7,8]$. If a magnetic field is applied, each magnetic particle will become a magnetic source, so that the magnetic scaffold material can play the role of bone tissue repair treatment. Once magnetic particles are exposed to an external magnetic field, they will be rapidly magnetized. Magnetic particles and magnetic fields work together to improve the effectiveness of bone tissue repair $[9,10]$. MNPs can be synthesized through different techniques including coprecipitation [11], microemulsion [12], hydrothermal synthesis [13], sol-gel process [14], polyol synthesis [15], flow injection [16], sonolysis/sonochemical method [17], microwave 
irradiation [18], electrochemical synthesis [19], solvothermal method [20], chemical vapor deposition [21], laser pyrolysis [22], green synthesis [23], and using biomass or biological templates.

Scaffolds used to reconstruct an injured bone must have sufficient mechanical strength to carry the load. Therefore, other types of scaffold materials, such as ceramics and biodegradable polymers, are usually not suitable for bone tissue engineering. Porous metals and alloy materials may be used as alternative scaffolds to promote new bone formation. However, other metal particles may release toxic substances and cause tissue pollution [24], and the issues can be overcome by using biodegradable metal materials such as irons and their alloys. In view of the advantages of IONPs, some researchers have incorporated $\mathrm{Fe}_{3} \mathrm{O}_{4}$ nanoparticles into tissue engineering biomaterials [25-27]. For example, Pan et al. [28] prepared $\mathrm{Fe}_{3} \mathrm{O}_{4}$ /polylactide composites with extrusion process, and they found that the composites containing IONPs had no cytotoxic effect on fibroblasts and enhanced osteogenesis in vitro experiments. Ge et al. [29] prepared a magnetic scaffold containing $\mathrm{Fe}_{3} \mathrm{O}_{4}$ /chitosan, which has high biocompatibility to $\mathrm{C}_{2} \mathrm{C}_{12}$ cells. Similarly, De Santis et al. designed a magnetic scaffold for bone tissue combining PCL and $\mathrm{Fe}_{3} \mathrm{O}_{4}$ with different ratios. The results showed that the nanoparticles mechanically enhanced the PCL matrix; the elastic modulus and maximum stress increased by about $10 \%$ and $30 \%$, respectively [30]. Thus, IONPs are expected to provide a strategy for bone repair. IONPs improve the three key factors of bone regeneration including stem cells, scaffolds, and growth factors via magnetic fields. Among the factors, magnetic cells' strategies contain cell labeling, targeting, and genetic modification. Magnetic scaffolds can enhance cell differentiation through magnetic-mechanical simulation [31]. And IONPs can also be used as delivery media for growth factors, drugs, and gene $[32,33]$.

\section{Synthesis and Application of IONPs in Bone Tissue Engineering}

2.1. Synthesis Method of IONPs. The preparation method has developed well due to its application value, and various element compositions have been used in magnetic nanomaterials, including $\mathrm{Fe}_{3} \mathrm{O}_{4}, \mathrm{Fe}, \mathrm{Co}, \mathrm{Ni}, \mathrm{MgFe}_{2} \mathrm{O}_{4}$, and $\mathrm{CoFe}_{2} \mathrm{O}_{4}$ [34-37]. The most common component of magnetic nanomaterials is $\mathrm{Fe}_{3} \mathrm{O}_{4}$, and the preparation methods of magnetic $\mathrm{Fe}_{3} \mathrm{O}_{4}$ mainly include dry and wet methods [38, 39]. Among them, the wet method is more commonly used and mainly includes the following technologies: hydrothermal method, solution thermal method, chemical coprecipitation method, ball milling method, sol-gel method, and atomic layer deposition method. The advantages and disadvantages of each preparation method are summarized (see Table 1).

\subsection{Application of IONPs in the Function of Scaffold}

2.2.1. Scaffold Material Type. Guiding and controlling the delivery of bioactive drugs to bone injuries has always been a hot research area. The design of the delivery platform plays a vital role in the treatment of bone diseases and the activa- tion of bone regeneration, because they can provide a suitable environment for the cell adhesion and growth and, at the same time, provide a valuable platform for delivery strategies [64]. The nanostructured materials used in the platform have the characteristics of biocompatibility, nontoxicity, and noncarcinogenicity. Several common nanomaterials for the attachment platform of IONPs are exhibited (see Table 2). Nanomaterials can be divided into organic materials and inorganic materials. Organic materials are a combination of the few lightest elements, especially hydrogen, nitrogen, and oxygen, as well as carbon-containing compounds located in organisms. Organic materials include lipids, liposomes, dendrimers, and polymers, including chitosan, gelatin, and collagen [65]. And inorganic materials refer to materials lacking carbon, which are widely used in in vivo and in vitro biomedical research [66].

IONPs with superparamagnetic properties have a high specific surface energy and are prone to agglomeration. Polymers, which can improve the stability of nanoparticle dispersion in water, are often used as wrapping materials on the surface of particles formatting shell-core structure. In addition, polymer-encapsulated magnetic nanoparticles have the characteristics of strong surface modification and easy modification or functionalization, which greatly broaden the application fields of magnetic materials. Polymers frequently used to encapsulate magnetic nanoparticles including proteins, dendrimers, liposomes, chitosan, glucose, starch, polyethylene glycol (PEG), polyvinyl alcohol (PVA), polyvinylpyrrolidone, and polyglyceryl acrylate (PGA). Among them, PEG is used for drug slow-release system because of its electrical neutrality, water solubility, low toxicity, and nonimmunogenic properties. Glycopolymers are often used in medical imaging studies to improve the diagnosis of diseased tissues such as tumors. PGA/PGMA is also a good class of polymers that has a stronger ability to bind to IONPs, greatly improving the stability of the particles. In addition, human-made biodegradable polymers are widely used as tissue engineering scaffold materials because they can be degraded to small molecules in vivo and excreted through the body metabolism. And they have good histocompatibility, mechanical properties, and controllable degradation rate.

There are many ways to synthesize IONP composite scaffolds, and the manufacturing process and the shortcomings shown are also different (see Table 3).

Among these methods, electrostatic spinning technology has become an important process for producing scaffolds due to its modulable properties and simplicity. The basic method of high-voltage electrostatic spinning technology is to apply a voltage of tens of thousands of volts between the jetting device and the receiving device, forming an electrostatic field. As the spinning fluid drips out of the jet, a jet is formed at the cone end of the droplet and is stretched in the electric field. The final result is the formation of long, irregular fibers on the receiving device, with fiber diameters typically in the tens to hundreds of the nanometer range. From the above description of the electrospinning principle, we find that the shape of the electrospun filament can be regulated by several parameters. These parameters include the viscosity and concentration of the spinning solution, the 
TABLE 1: Synthesis method of IONPs.

\begin{tabular}{|c|c|c|c|}
\hline Method & Advantage & Disadvantage & Reference \\
\hline Organic based & High particle dispersion & Unruly IONPs' appearance & {$[40-42]$} \\
\hline Hydrothermal/solvothermal & $\begin{array}{c}\text { Simple operation } \\
\text { High reaction efficiency } \\
\text { Suitable for wider temperature range }\end{array}$ & $\begin{array}{l}\text { Hard to replicate metastable phase and } \\
\text { nanomorphology in other ways }\end{array}$ & [43-47] \\
\hline Coprecipitation & $\begin{array}{c}\text { Simple operation } \\
\text { High-yield }\end{array}$ & $\begin{array}{l}\text { Poor controllability of its particle size } \\
\text { and distribution }\end{array}$ & {$[48-51]$} \\
\hline Ball milling & Granularity reproducibility & $\begin{array}{c}\text { IONP aggregation } \\
\text { Expensive } \\
\text { Long cycle } \\
\text { Hard to realize industrial production }\end{array}$ & [52-55] \\
\hline Sol-gel & $\begin{array}{l}\text { Small particle size } \\
\text { Good dispersion }\end{array}$ & $\begin{array}{c}\text { Expensive } \\
\text { Long duration } \\
\text { Easy to shrink during drying }\end{array}$ & {$[56-60]$} \\
\hline Atomic layer deposition & $\begin{array}{l}\text { Accurate thickness control } \\
\text { Good uniformity }\end{array}$ & Slow deposition rate & {$[61-63]$} \\
\hline
\end{tabular}

conductivity, the charge concentration of the solution, the electric field strength/voltage surface tension, the distance between the needle and the collecting screen, the design and placement of the needle tip, and the composition and geometry of the collecting screen. Of course, there are other factors like ambient constant, dipole moment, dielectric constant, and surface tension that also affect high-voltage electrostatic spinning.

2.2.2. IONPs Enhance Scaffold Function. Artificial bone transplantation has been extensively studied for bone repair due to less immune rejection and low disease transmission ability [102, 103]. Bone morphogenetic proteins and transformation factors are usually incorporated into artificial scaffolds to improve cell viability. However, there is still a phenomenon of slow cell binding. If magnetic field stimulation activates more receptors on the cell surface and further activates related signal pathway, the cell activity will be enhanced [104, 105]. Magnetic scaffolds can attract growth factors and stem cells to migrate in the body through magnetic drive and promote bone repair and regeneration [106]. In addition, magnetic field stimulation can promote the integration of the scaffold with the host bone and increase calcium content and new bone density, thereby accelerating bone healing [107-109]. At present, the role of magnetic scaffold in promoting cell proliferation and new bone tissue growth has been confirmed [110]. The magnetic scaffold has a wide range of components including biological macromolecules, synthetic polymers, polyethylene glycol, and inorganic materials [111-115].

Liu et al. [116] fabricated a magnetic coating composed of $\mathrm{Fe}_{3} \mathrm{O}_{4}$ nanoparticles and polyamine on the surface of the scaffold, thereby enhancing the cell attachment, proliferation, and bone differentiation of mesenchymal stem cell (MSC) in vitro, and forming new bones at the defect of the rabbit femur. It is found that the magnetic $\mathrm{Fe}_{3} \mathrm{O}_{4} / \mathrm{PDA}$ coating is related to strengthening the regulation signal pathway by protein analysis. Shuai et al. [117] constructed a magnetic microenvironment by selectively sintering $\mathrm{Fe}_{3} \mathrm{O}_{4}$ magnetic nanoparticles on the PLLA/PGA scaffold. Each nanoparticle in the environment provides a nanometer-scale magnetic field to activate the cell response. The in vitro results show that the magnetic scaffold not only stimulates cell adhesion and activity but also improves the rate of growth and alkaline phosphatase activity (see Figure 1). Yang et al. [118] used calcium phosphate cement (CPC) and IONPs to prepare a new type of scaffold and explored the effect of the new composite material on the formation and bone formation of human dental pulp stem cells (hDPSC). They found that the addition of IONPs greatly promote the bone formation of hDPSC, enhanced mechanical strength and cell activity, and increased the expression of bone marker genes by $1.5-2$ times.

Quite a few studies have shown that IONPs have a significant effect on the function of the scaffold. In fact, the 3D platform with IONPs shows tighter cell-to-cell connections, and highly developed filamentous protrusions (increased number and extension length) enhance the interaction between cells and the platform. The distribution of nanoparticles on the surface of the 3D scaffold increased the surface area of the scaffold, enhanced the mechanical signal transduction of cells, and stabilized the cell's anchoring to the matrix, thus promoting the cell adhesion process. Adding IONPs to the 3D scaffold significantly increases the expression of the osteogenic transcription factor RUNX2 and its two downstream factors. IONPs may promote bone formation through different mechanisms, but they rely more on magnetic genetic responses that activate intracellular magnetic receptors and generate endogenous magnetic fields to promote bone formation even in the absence of external magnetic fields [119].

When nanoparticles are absorbed on the surface of the tissue scaffold, they are in direct contact with the cells and may have unknown effects on the cells through ingestion. Hsin-Yi Lin et al. discussed how to use a three-dimensional printing device to make a chitosan hydrogel scaffold and embed nanoparticles in the hydrogel, so that the surrounding cells do not directly contact the nanoparticles. Some studies have shown that the coupling force induced by the magnetic chitosan scaffold promotes the growth and mineralization of bone cells. 
TABLE 2: Types of materials for the attachment platform of IONPs.

\begin{tabular}{|c|c|c|c|c|}
\hline $\begin{array}{l}\text { Types of } \\
\text { nanomaterials }\end{array}$ & Description & $\begin{array}{c}\text { Size } \\
(\mathrm{nm})\end{array}$ & Applications & Reference \\
\hline Lipid & Small hydrophobic or amphiphilic molecules & $<100$ & $\begin{array}{l}\text { Nanocarriers for anticancer } \\
\text { Drug doxorubicin } \\
\text { Osteoblastic bone formation } \\
\text { Osteoporosis treatment }\end{array}$ & {$[67-70]$} \\
\hline Liposome & $\begin{array}{l}\text { Same bilayer structure as the skin cell membrane structure } \\
\text { and excellent moisturizing effect on the skin }\end{array}$ & $>25$ & $\begin{array}{l}\text { High encapsulation of } \\
\text { hydrophilic } \\
\text { Drug delivery } \\
\text { Growth factor delivery } \\
\text { Therapeutic gene delivery } \\
\text { Used as a template }\end{array}$ & [71-73] \\
\hline Dendrimers & Organic molecules with dendritic structure & $<10$ & Multidrug delivery system & $\begin{array}{l}{[71,74,} \\
75]\end{array}$ \\
\hline Chitosan & A natural nontoxic linear biopolymer & $20-200$ & $\begin{array}{c}\text { Scaffolds } \\
\text { Drug delivery } \\
\text { Support chondrocyte adhesion } \\
\text { Implant coating } \\
\text { Osteogenic differentiation }\end{array}$ & {$[76-80]$} \\
\hline Collagen & $\begin{array}{l}\text { The main structural protein of soft and hard tissues } \\
\text { in living organisms }\end{array}$ & - & $\begin{array}{l}\text { Drug delivery } \\
\text { Scaffolds }\end{array}$ & {$[81]$} \\
\hline Gelatin & Derivatives of collagen & $<200$ & $\begin{array}{c}\text { Scaffolds } \\
\text { Drug-loaded gelatin } \\
\text { nanoparticles } \\
\text { Promote cell growth }\end{array}$ & {$[82,83]$} \\
\hline PLGA & A degradable functional polymer organic compound & $100-250$ & $\begin{array}{c}\text { Drug delivery } \\
\text { Scaffolds } \\
\text { Nanostructured film } \\
\text { Enhanced cell attachment and } \\
\text { growth } \\
\text { Promote gene expression }\end{array}$ & [84-87] \\
\hline Carbon nanotubes & $\begin{array}{l}\text { With cylindrical or tapered structure of different } \\
\text { diameters and lengths }\end{array}$ & $20-100$ & $\begin{array}{c}\text { Drug delivery } \\
\text { Biosensing } \\
\text { Scaffolds }\end{array}$ & [88-91] \\
\hline
\end{tabular}

TABle 3: Synthesis method of IONP composite scaffolds.

\begin{tabular}{|c|c|c|c|}
\hline Synthesis method & Advantages & Disadvantages & Reference \\
\hline $\begin{array}{l}\text { Traditional method } \\
\text { (physical adsorption) }\end{array}$ & Simple, cheap, stable performance & $\begin{array}{c}\text { Lack of control measures for magnetic } \\
\text { field gradients }\end{array}$ & {$[92,93]$} \\
\hline $\begin{array}{l}\text { IONPs mixed with other } \\
\text { ingredients }\end{array}$ & Stable performance, excellent mechanical properties & $\begin{array}{l}\text { Difficult to control the surface } \\
\text { characteristics of the bracket }\end{array}$ & [94-97] \\
\hline Electrospinning & $\begin{array}{l}\text { Easy to operate, easy to control the surface } \\
\text { characteristics of the bracket }\end{array}$ & Low output and low strength & [98-100] \\
\hline $3 \mathrm{D}$ printing & $\begin{array}{c}\text { Good stability, good three-dimensional structure, } \\
\text { high efficiency }\end{array}$ & Expensive, material limitations & {$[101]$} \\
\hline
\end{tabular}

Under the action of inductively coupled magnetic force, the signal transduction in bone cells is achieved through the release of intracellular $\mathrm{Ca}+$. This leads to an increase in cytoplasmic $\mathrm{Ca}$ ions and an increase in cytoskeletal calmodulin. The increase in cytoplasmic calcium in bone cells will cause cellular bones to shrink. Calcium-dependent contraction promotes the release of extracellular vesicles. These extracellular vesicles contain key bone regulatory proteins, including cellu- lar skeletal calmodulin. Calmodulin is a calcium-sensing protein that is involved in signal pathways that regulate many key processes in bone cells, such as growth, cell division, and movement (see Figure 2).

In addition to its outstanding performance in promoting cell proliferation and osteogenic differentiation, the excellent mechanical strength of the magnetic scaffold also deserves our attention. For example, Ghorbani et al. investigated the 


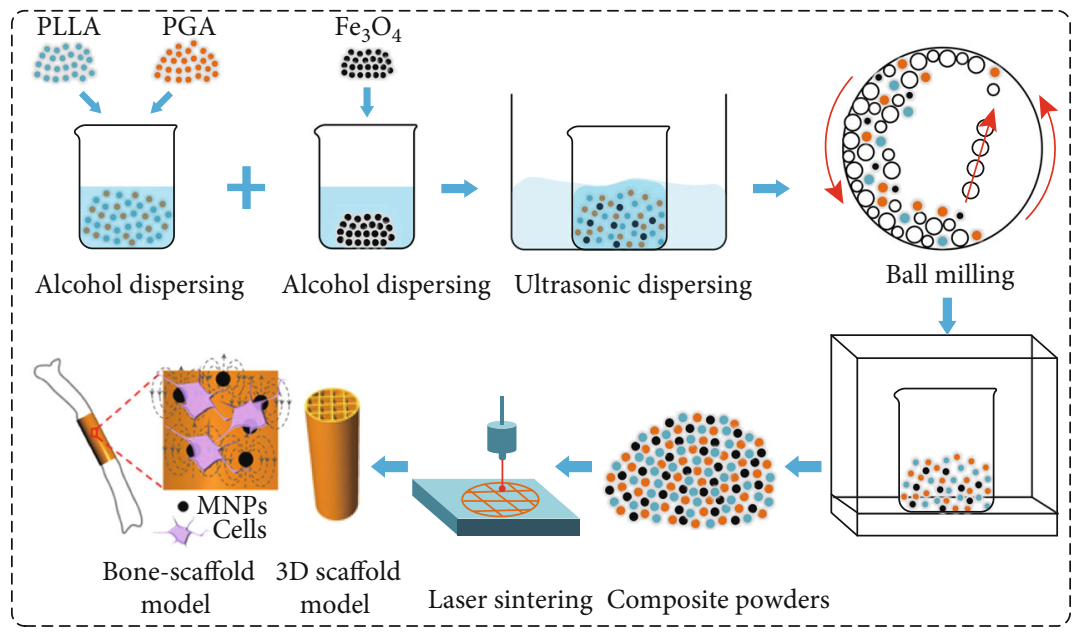

FIGURE 1: Schematic of the magnetic scaffold preparation process. Reproduced with permission from [117].
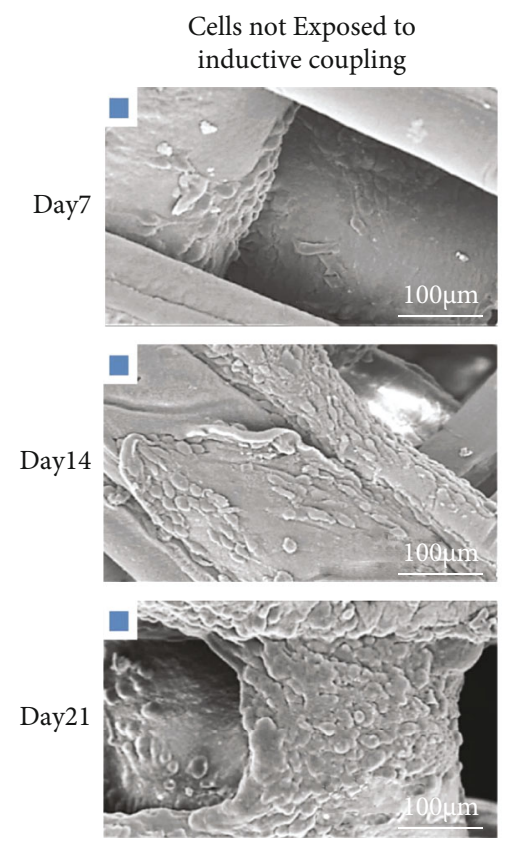

(a)
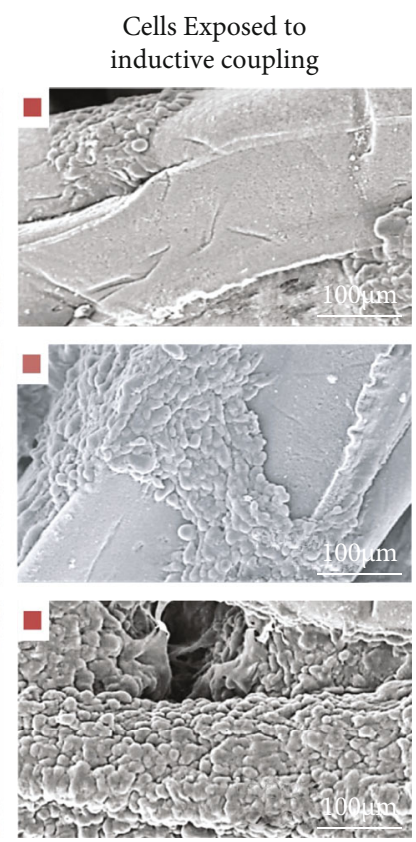
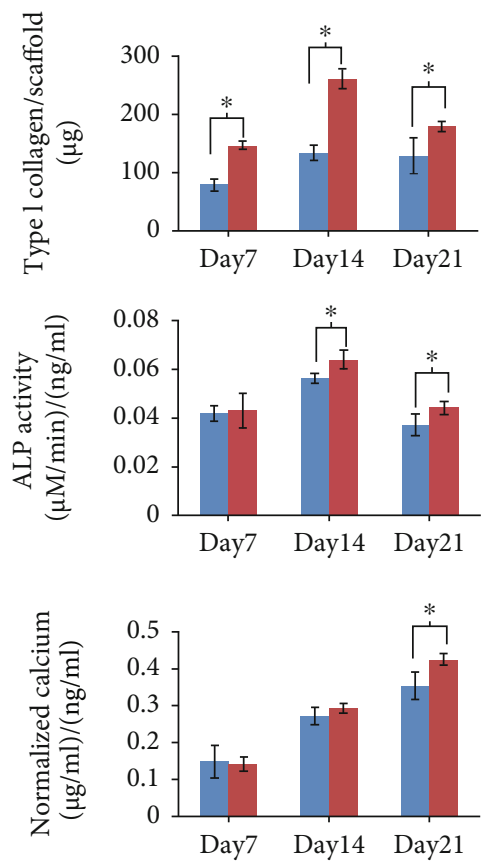

(b)

Figure 2: (a, b) Cell surface morphology and osteogenic differentiation with and without the inductive coupling magnetic force for 7 , 14, and 21 days. (a) The morphology of osteoblast cells on the chitosan hydrogel scaffolds. (b) Osteoblast cell proliferation and differentiation. Reproduced with permission from [120].

effect of IONPs on the scaffold structure. Compared with scaffolds without IONPs, scaffolds with IONPs reduced the pore size, thus improving the mechanical strength of the scaffold, but the absorption capacity and biodegradation ratio were reduced [121]. Similar to Ghorbani et al.'s study, Kim et al. also found that the mechanical stiffness of the PCL scaffold increased significantly with the addition of IONPs. The initial adhesion of cells to the magnetic scaffold was substantially increased by 1.4 -fold compared to the pure PCL scaffold [122]. Wang et al. fabricated borosilicate bioactive glass scaffolds loaded with different amounts (5-15 wt\%) of $\mathrm{Fe}_{3} \mathrm{O}_{4}$ nanoparticles and evaluated their performance in vitro and in vivo. They found that the $\mathrm{Fe}_{3} \mathrm{O}_{4}$ content was proportional to the compressive strength of the scaffold, and the compressive strength of the scaffolds increased with increasing content of IONPs, from $2.6 \pm 0.6 \mathrm{MPa}$ for the BG scaffolds to $3.6 \pm 0.6 \mathrm{MPa}$ for the scaffolds loaded with $15 \mathrm{wt} \% \mathrm{Fe}_{3} \mathrm{O}_{4}$ [123]. In the meantime, that scaffold has the largest magnetic saturation and highest temperature of aqueous suspension.

These findings suggest that the scaffold with IONPs has excellent physicochemical, magnetic, mechanical, and biological 

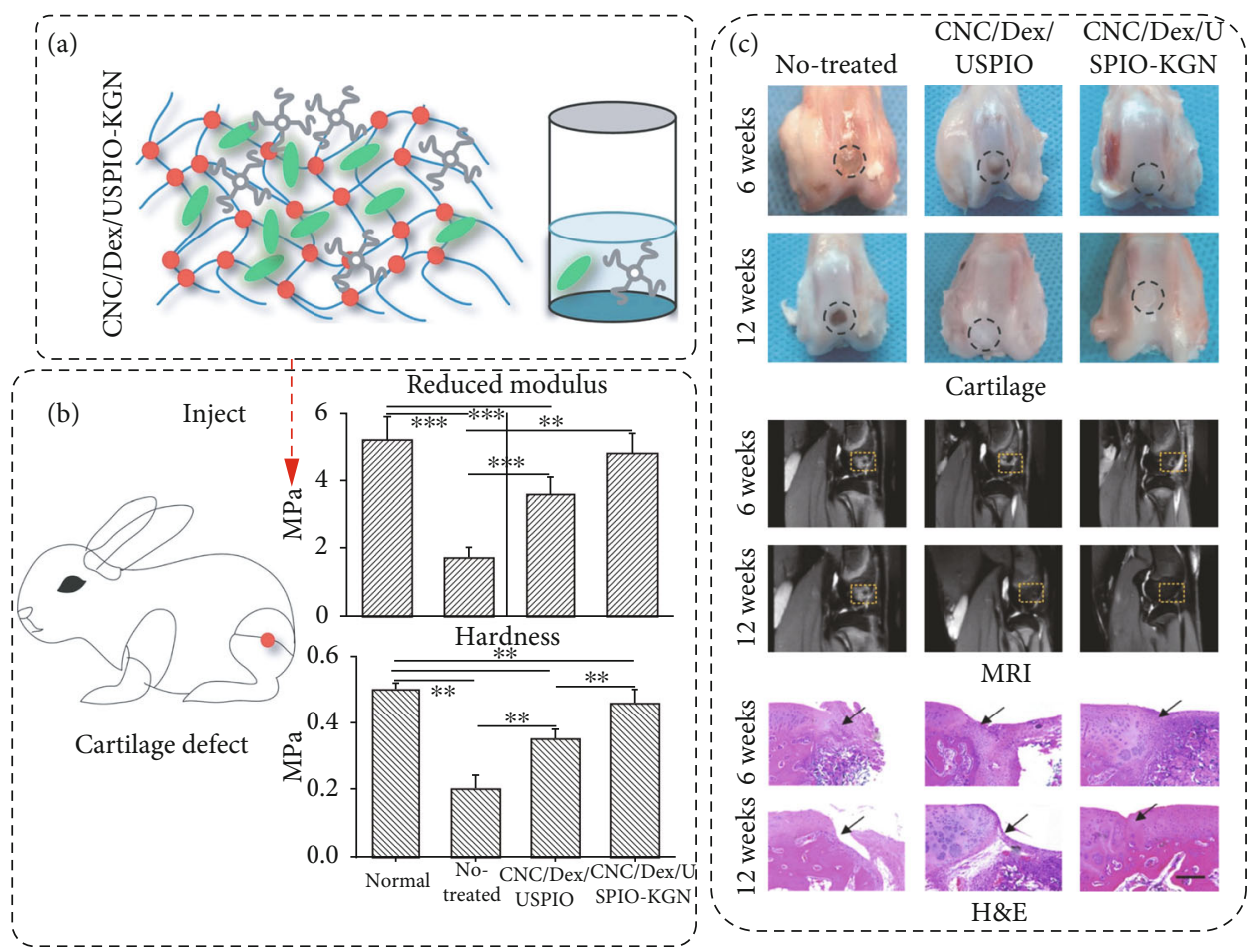

FIGURE 3: Synthesis in vitro and physicochemical properties in rabbit cartilage of CNC/Dex/USPIO-KGN. (a) Schematic illustration of preparation and utilization of USPIO-labeled Dex/CNC/USPIO-KGN hydrogels for engineering artificial cartilage repair. (b) Reduced modulus and hardness (reduced modulo is a "combined" modulus of the tip and the sample and can be directly evaluated from analysis of stress-strain data according to specific equations). (c) Observations of cartilage harvested; MRI and H\&E during 6 weeks and 12 weeks. H\&E staining shows that the neocartilage integrated with the adjacent normal cartilage. Reproduced with permission from [127].

properties, supporting the potential application of magnetic scaffolds for bone repair and regeneration.

\subsubsection{IONPs Promote Stem Cell Differentiation. In addition} to scaffolds, stem cells are another vital factor in tissue regeneration. In recent years, although stem cell therapy has provided a strategy for large-scale bone repair and has been successful in the treatment of animal bone defect models, these traditional stem cell transplants have not achieved the desired effect [124]. With the development of materials science and chemical biology, people have been trying to use IONPs as a tool for research and control of stem cells for many years [125]. By combining IONPs with an external magnetic field, it will affect the cell adhesion, proliferation, movement and distribution, and osteogenic differentiation of stem cells. In addition, IONPs can be used to label cells for in vivo tracking and monitoring.

MSCs are a key participant in bone regeneration, and promoting the differentiation of MSCs is an important basis for evaluating the performance of nanoparticles. The combination of different polymers and IONPs greatly promote the differentiation of MSCs. Jia et al. [126] synthesized mediumporous silicon-coated magnetic $\mathrm{Fe}_{3} \mathrm{O}_{4}$ nanoparticles and evaluated their potential to accelerate bone regeneration in a rat osteoporosis model. After X-ray imaging, micro-CT, mechanical testing, histological examination, and immunochemical analysis, local injection of MNPs significantly accelerated bone regeneration. Yang et al. [127] transplanted kartogenin (KGN), which can promote the differentiation of bone marrow-derived mesenchymal stem cells into chondrocytes, onto a modified magnetic oxide surface, and then integrated into the cellulose nanocrystalline hydrogel. Release and recruit endogenous host cells and differentiate BMSCs into chondrocytes, thereby achieving original cartilage regeneration. The regenerated cartilage tissue is very similar to a natural cartilage. This innovative diagnosis and treatment system improve the convenience and effectiveness of cartilage regeneration (see Figure 3).

$\mathrm{Xu}$ et al. [128] prepared hollow IONPs, HMFN, which is of spherical shape with a diameter of about 320 nanometers. It has a negative charge on the surface and has huge supernegative magnetic properties. The $-\mathrm{OH}$ bond in it improves the affinity of nanoparticles. For water and biocompatibility, as a result, it was found that electromagnetic fields can use intracellular supersuspended magnetic nanoparticles to manipulate the bone differentiation of BMSCs.

In addition, human dental pulp stem cells (hDPSCs) also provide great potential for research of bone tissue engineering. Their advantages include easy isolation, nonimmunogenicity, strong proliferation, and differentiation ability, similar to bone marrow stem cells (BMSCs) [129]. The osteogenic differentiation ability of hDPSCs has been fully confirmed by previous studies, which is manifested by increased ALP activity [130] and increased expression of bone-specific markers $[131,132]$. The $\mathrm{WNT} / \beta$-catenin signaling pathway plays an important role in osteogenesis. Previous studies have shown that by activating the SMAD pathway or interacting with the WNT pathway to upregulate 


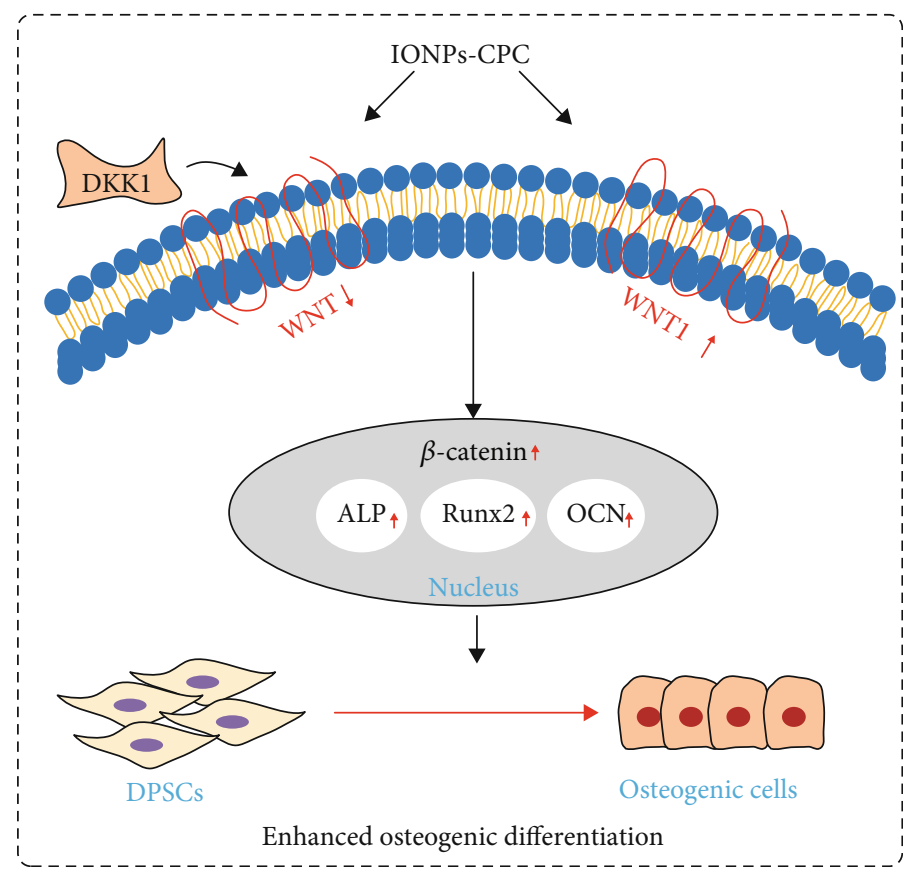

FIGURE 4: WNT signaling pathway promotes osteoblast differentiation.

osteogenic genes, IONPs can promote stem cells by upregulating BMP2, which plays a key role in bone morphogenesis. They added hydrophilic IONP solution to CPC powder to prepare IONP-CPC scaffolds and explored the effect of new composite materials on the formation of bone matrix and osteogenic differentiation of hDPSCs. As the ionosphere content increases, the color of the scaffold turns darker, and the surface of the scaffold forms agglomerates, which significantly enhances the adsorption of proteins. Through the analysis of the WNT pathway, it was found that CPC+IONPs can significantly enhance the expression of $\beta$-catenin protein, proving its important role in the osteogenic differentiation of stem cells (see Figure 4) [118]. In fact, another study also confirmed that IONPs can activate the BMP/SMAD pathway [133].

2.2.4. Marking and Positioning of IONPs. Cell migration, distribution, survival, and differentiation play a crucial role in therapeutic efficacy [134]. We understand that these parameters can optimize cell selection, administration route, and therapeutic dose and provide cell-based therapy for specific clinical applications. To solve this problem, researchers have been looking for tools that allow real-time, quantitative, and long-term monitoring of cell behavior in the body. This phenomenon is called cell tracking. IONPs are used as an NMR contrast agent for cell tracking [135].

Because the healing potential of the articular cartilage is limited, the treatment of osteoporotic defects continues to pose a major challenge to patients and orthopedic surgeons. MSCs have a therapeutic potential for the treatment of osteoporotic pain and pathology. However, it is necessary to use appropriate stem cell labels and imaging agents to decipher its role after transplantation. Silva et al. [136] incubated MSCs with magnetic nanoparticles and used external magnetic fields to guide magnetized MSCs in vitro and enhanced their retention in the lungs in vivo. The results showed that MT improved MSC translocation and expression of chemical hormone receptor. Shelat et al. [137] evaluated the efficacy of bone marrow-derived mesenchymal stem cells (BMSCs) for the treatment of osteoporosis defects in rats and used L-lysine functionalized IONPs (lys-IONPs) to treat stem cells. In vivo monitoring showed that the particles can be used as long-term stem cell markers and imaging agents. Yao et al. [138] used amine-modified silicon-coated nanoparticles to label bone marrow-derived mesenchymal stem cells and then evaluated the stem cell potential. The study found that after labeling, the viability of BM-MSC remained good and the migration ability was enhanced and had no effect on bone production and adipogenesis, which means that this kind of nanoparticles can not only serve as an ideal tracking marker but also become an accelerator for stem cell positioning during tissue repair (see Figure 5). In addition, scholars have also discovered the advantages of magnetic IONPs as markers in the treatment of diseases such as ischemic heart disease and pulmonary fibrosis [139, 140].

2.2.5. Security Issues of IONPs. IONPs are among the most versatile and safe nanoparticles for a variety of biomedical applications. The dramatic increase in the use of nanoparticles in research, industry, and medicine raises many questions about potential toxicity [141], since the nanoscale properties can potentially induce cytotoxicity by impairing the functions of mitochondria, nucleus, and DNA [141143]. It is well known that excess reactive oxygen species (ROS), including superoxide anions, hydroxyl radicals, and nonradical hydrogen peroxide, can be toxic intracellularly and in vivo $[141,144,145]$. The ROS can be generated from the leaching of iron ions from the surface degradation by enzymatic degradation. Furthermore, ROS can react with macromolecules and damage cells by peroxidizing lipids, 


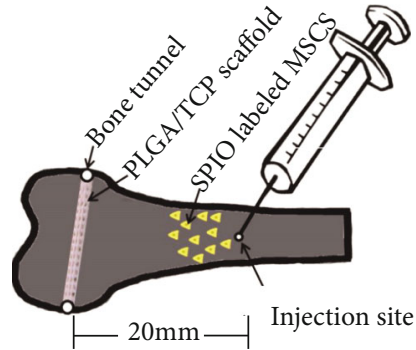

(a)

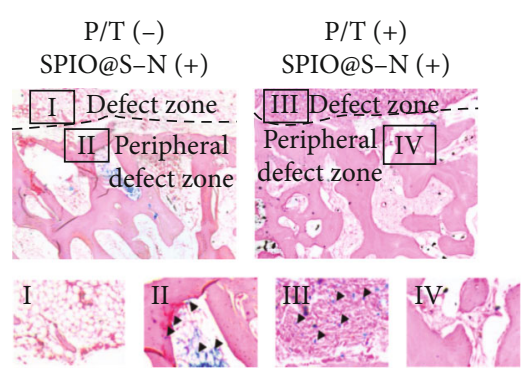

(b)

FIgure 5: (a, b) Marking and positioning of IONPs. (a) Rabbit SAON bone defect model was established, and PLGA/TCP was implanted into the rabbit at the distal femur to track BM-MSC migration in vivo. (b) Dynamic MRI was performed at day 0 and day 7 , respectively, after implantation. Reproduced with permission from [140].

changing proteins, disrupting DNA, interfering with signaling functions, modulating gene transcription, and finally causing cell death either by apoptosis or necrosis. Another mechanism by which IONPs can induce toxicity is via iron overload. Since IONPs require magnetic targeting to specific tissues [146], high concentrations of free iron ions may lead to abnormal cellular responses including cytotoxicity, oxidative stress, epigenetic events, inflammation, and DNA damage that may trigger carcinogenesis or have significant effects on offspring [142, 147-150].

The cytotoxicity of IONPs is highly dependent on a number of factors related to their physical properties, such as size, shape, and surface coating. The type of surface coating materials of IONPs and their decomposition products are important in determining their toxicity [151]. As mentioned previously, there are many polymers that can be used to coat IONPs; however, some studies have shown that PEGcoated IONPs produce negligible aggregation in cell culture media and reduce nonspecific uptake by macrophages [152], while dextran-coated IONPs can lead to cell death and reduced proliferation with observable visible membrane disruption $[153,154]$. The oxidation state of iron $\left(\mathrm{Fe}^{2+}\right.$ or $\mathrm{Fe}^{3+}$ ) in IONPs is an additional key factor that determines the cytotoxicity of IONPs [150]. It has been demonstrated that maghemite $\left(\mathrm{Fe}_{2} \mathrm{O}_{3}\right)$ with an $\mathrm{Fe}^{2+} / \mathrm{Fe}^{3+}$ ratio of 0.118 has a more significant genotoxicity than magnetite $\left(\mathrm{Fe}_{3} \mathrm{O}_{4}\right)$ with an $\mathrm{Fe}^{2+} / \mathrm{Fe}^{3+}$ ratio of 0.435 . More efforts are needed to design and prepare IONPs with good chemical stability.

In vivo, the toxicity of IONPs is dose dependent and is also related to the type of tissue cells on which they act. For example, Hanini et al. [155] reported that IONPs in vivo can induce toxicity in the liver, kidneys, and lungs while the brain and heart organs remained unaffected. Additionally, hemocompatibility is also an aspect that should be taken into account for the in vivo application of IONPs. If IONPs are incompatible with biological fluids such as blood, this can trigger coagulation and clot formation through adsorption of plasma proteins, platelet adhesion, and activation of the complement cascade. IONPs will exist in different proportions in different organs of the body; how to remove the excess particles is also related to the toxic side effects. Generally, clearance and opsonization of IONPs depend on their sizes and surface characteristics [156, 157]. For example, $55 \%$ oleic acid/pluronic-coated IONPs of injected dos- age were accumulated in the liver of a rat. However, in the same animal model, $25 \%$ of injected dextran-coated IONPs was eliminated via urine and feces [158]. Therefore, the toxic effects of IONPs on humans can be effectively reduced by controlling the physical properties of IONPs and selecting the appropriate type of surface coating material and the dose of IONPs. Also, more attention should be paid to the kinetic and metabolic mechanisms of IONPs with different surface coatings, which would allow the development of predictive models of nanotoxicity.

\section{Summary and Prospect}

We briefly describe the synthesis method of IONPs and the merit and demerit of each method. And the applications of the IONPs in the function of scaffold are also elaborated. Among them, we firstly mentioned the material used to make the scaffold and statistics on their size. Each material has unique properties including nanocarriers for anticancer, drug doxorubicin, osteoblastic bone formation, and osteoporosis treatment. And then, we have mentioned the merit and demerit of several scaffold synthesis methods. Furthermore, the mechanism by which IONPs enhance the function of the scaffold is described. IONPs can impart a magnetic effect to the scaffold, which can attract growth factors and stem cells to migrate in the body, and promote bone repair and regeneration. IONPs can also be used as accelerators to accelerate the binding of the scaffold to the host bone and enhance related signal pathways to promote the attachment, proliferation, and bone differentiation of mesenchymal stem cells. At the same time, as a marker and imaging agent, it is an important tool for drug delivery and stem cell localization.

Through the above literature research, we have summarized the development status and development direction of IONPs. (a) How to precisely control the arrangement of the IONPs to obtain a better magnetocaloric effect has broad prospects. (b) There are many ways to prepare composite scaffolds of iron oxide particles, all of which have excellent performance and significant shortcomings in specific scenarios. How to obtain a scaffold that can control the surface characteristics of the scaffold and has high yield and low cost will become the focus of research. (c) How to maintain longlasting and effective stem cell characteristics is the key to successful treatment. Therefore, for cells expanded in vitro, 
maintaining a stable cell phenotype and reducing the necrosis and loss of the cells at the defect site after transplantation in vitro are necessary for bone defect repair. (d) At present, most researches on IONPs focus on labeling methodologies and monitoring curative effects, but there are not many studies on their effects on labeled cells. IONPs have different effects on different types of cells, even the same type of cell, in different aspects. Functional activities also react differently to IONPs. Therefore, it is necessary to extensively study the short-term and long-term potential cytotoxicities of IONPs to different labeled cells, which is an important reference for avoiding the adverse reactions of IONPs when cell magnetic labeling really enters the clinical trial stage in the future.

With the in-depth research of human cells and virus particles, the continuous improvement of the feasibility and practicability of nanoparticles as drug carriers will inevitably provide a breakthrough in the research of drug carrier systems. It is reasonable to believe that the multifunctional magnetic nanodrug carrier with fluorescence detection, multiple targeting, efficient drug loading, quantitative timereleased drug, and nontoxic side effects is of great significance for the diagnosis and treatment of major diseases such as cancer.

\section{Data Availability}

The data used to support the findings of this study are included within the article.

\section{Conflicts of Interest}

There are no conflicts of interest in this study.

\section{Authors' Contributions}

All authors have read and approved this version of the article, and due care has been taken to ensure the integrity of the work.

\section{Acknowledgments}

This research was supported by National Natural Science Foundation of China (No. 11972065) and Beijing Natural Science Foundation (L202006).

\section{References}

[1] H. Y. Xu and N. Gu, "Magnetic responsive scaffolds and magnetic fields in bone repair and regeneration," Frontiers of Materials Science, vol. 8, no. 1, pp. 20-31, 2014.

[2] E. Chung, A. C. Sampson, and M. N. Rylander, "Influence of heating and cyclic tension on the induction of heat shock proteins and bone-related proteins by MC3T3-E1 cells," BioMed Research International, vol. 2014, Article ID 354260, 16 pages, 2014.

[3] M. Quittan, O. Schuhfried, G. F. Wiesinger, and V. FialkaMoser, "Clinical effectiveness of magnetic field therapy-a review of the literature," Acta Medica Austriaca, vol. 27, no. 3, pp. 61-68, 2000.
[4] M. Gujjalapudi, C. Anam, P. Mamidi, R. Chiluka, A. G. Kumar, and R. Bibinagar, "Effect of magnetic field on bone healing around endosseous implants - an in-vivo study," Journal of Clinical and Diagnostic Research, vol. 10, no. 10, pp. ZF01-ZF04, 2016.

[5] R. V. Ferreira, P. P. Silva-Caldeira, E. C. Pereira-Maia et al., "Bio-inactivation of human malignant cells through highly responsive diluted colloidal suspension of functionalized magnetic iron oxide nanoparticles," Journal of Nanoparticle Research, vol. 18, no. 4, p. 92, 2016.

[6] A. Özbey, M. Karimzadehkhouei, S. E. Yalçın, D. Gozuacik, and A. Koşar, "Modeling of ferrofluid magnetic actuation with dynamic magnetic elds in small channels," Microfluidics and Nanofluidics, vol. 18, no. 3, pp. 447-460, 2015.

[7] A. J. Theruvath, H. Nejadnik, A. M. Muehe et al., "Tracking cell transplants in femoral osteonecrosis with magnetic resonance imaging: a proof-of-concept study in patients," Clinical Cancer Research, vol. 24, no. 24, pp. 6223-6229, 2018.

[8] Y. Xia, J. Sun, L. Zhao et al., "Magnetic field and nanoscaffolds with stem cells to enhance bone regeneration," Biomaterials, vol. 183, pp. 151-170, 2018.

[9] D. Fan, Q. Wang, T. Zhu et al., "Recent advances of magnetic nanomaterials in bone tissue repair," Frontiers in Chemistry, vol. 8, 2020.

[10] Y. Zhao, T. Fan, J. Chen et al., "Magnetic bioinspired micro/nanostructured composite scaffold for bone regeneration," Colloids and Surfaces. B, Biointerfaces, vol. 174, pp. 70-79, 2019.

[11] M. I. Khalil, "Co-precipitation in aqueous solution synthesis of magnetite nanoparticles using iron(III) salts as precursors," Arabian Journal of Chemistry, vol. 8, no. 2, pp. 279284, 2015.

[12] M. A. Malik, M. Y. Wani, and M. A. Hashim, "Microemulsion method: A novel route to synthesize organic and inorganic nanomaterials: 1st Nano Update," Arabian Journal of Chemistry, vol. 5, no. 4, pp. 397-417, 2012.

[13] T. J. Daou, G. Pourroy, S. Bégin-Colin et al., "Hydrothermal synthesis of monodisperse magnetite nanoparticles," Chemistry of Materials, vol. 18, no. 18, pp. 4399-4404, 2006.

[14] Z. I. Takai, M. K. Mustafa, S. Asman, and K. A. Sekak, "Preparation and characterization of magnetite $\left(\mathrm{Fe}_{3} \mathrm{O}_{4}\right)$ nanoparticles by sol-gel method," International Journal of Nanoelectronics and Materials, vol. 12, pp. 37-46, 2019.

[15] R. Hachani, M. Lowdell, M. Birchall et al., "Polyol synthesis, functionalisation, and biocompatibility studies of superparamagnetic iron oxide nanoparticles as potential MRI contrast agents," Nanoscale, vol. 8, no. 6, pp. 3278-3287, 2016.

[16] G. Salazar-Alvarez, M. Muhammed, and A. Zagorodni, "Novel flow injection synthesis of iron oxide nanoparticles with narrow size distribution," Chemical Engineering Science, vol. 61, no. 14, pp. 4625-4633, 2006.

[17] A. Hassanjani-Roshan, M. R. Vaezi, A. Shokuhfar, and Z. Rajabali, "Synthesis of iron oxide nanoparticles via sonochemical method and their characterization," Particuology, vol. 9, no. 1, pp. 95-99, 2011.

[18] E. Aivazoglou, E. Metaxa, and E. Hristoforou, "Microwaveassisted synthesis of iron oxide nanoparticles in biocompatible organic environment," AIP Advances, vol. 8, article 48201, 2017.

[19] M. Starowicz, P. Starowicz, J. Żukrowski et al., "Electrochemical synthesis of magnetic iron oxide nanoparticles with 
controlled size," Journal of Nanoparticle Research, vol. 13, no. 12, pp. 7167-7176, 2011.

[20] Y. Huang, L. Zhang, W. Huan, X. Liang, X. Liu, and Y. Yang, "A study on synthesis and properties of $\mathrm{Fe}_{3} \mathrm{O}_{4}$ nanoparticles by solvothermal method," Glass Physics and Chemistry, vol. 36, no. 3, pp. 325-331, 2010.

[21] D. Wei, Y. Liu, L. Cao et al., "A magnetism-assisted chemical vapor deposition method to produce branched or ironencapsulated carbon nanotubes," Journal of the American Chemical Society, vol. 129, no. 23, pp. 7364-7368, 2007.

[22] O. Bomati-Miguel, L. Mazeina, A. Navrotsky, and S. Veintemillas-Verdaguer, "Calorimetric study of maghemite nanoparticles synthesized by laser-induced pyrolysis," Chemistry of Materials, vol. 20, no. 2, pp. 591-598, 2008.

[23] V. C. Karade, P. P. Waifalkar, T. D. Dongle et al., "Greener synthesis of magnetite nanoparticles using green tea extract and their magnetic properties," Materials Research Express, vol. 4, no. 9, p. 96102, 2017.

[24] V. S. A. Challa, S. Mali, and R. D. K. Misra, "Reduced toxicity and superior cellular response of preosteoblasts to Ti-6Al$7 \mathrm{Nb}$ alloy and comparison with Ti-6Al-4V," Journal of Biomedical Materials Research Part A, vol. 101, no. 7, pp. 2083-2089, 2013.

[25] T. Long, Y. P. Guo, S. Tang, Y. J. Guo, and Z. A. Zhu, "Emulsion fabrication of magnetic mesoporous carbonated hydroxyapatite microspheres for treatment of bone infection," RSC Advances, vol. 4, no. 23, pp. 11816-11825, 2014.

[26] J. Li, Y. Hu, J. Yang et al., "Hyaluronic acid-modified $\mathrm{Fe}_{3} \mathrm{O}_{4} @ \mathrm{Au}$ core/shell nanostars for multimodal imaging and photothermal therapy of tumors," Biomaterials, vol. 38, pp. 10-21, 2015.

[27] W. Chen, T. Long, Y. J. Guo, Z. A. Zhu, and Y. P. Guo, "Magnetic hydroxyapatite coatings with oriented nanorod arrays: hydrothermal synthesis, structure and biocompatibility," Journal of Materials Chemistry B, vol. 2, no. 12, pp. 16531660, 2014

[28] Y. H. Pan, H. T. Wang, T. L. Wu, K. H. Fan, H. M. Huang, and W. J. Chang, "Fabrication of $\mathrm{Fe}_{3} \mathrm{O}_{4}$ /PLLA composites for use in bone tissue engineering," Polymer Composites, vol. 38, 2016.

[29] J. H. Ge, M. Z. Zhai, Y. Zhang, J. Bian, and J. Wu, "Biocompatible $\mathrm{Fe}_{3} \mathrm{O}_{4}$ /chitosan scaffolds with high magnetism," International Journal of Biological Macromolecules, vol. 128, pp. 406-413, 2019.

[30] R. de Santis, A. Gloria, T. Russo et al., "A basic approach toward the development of nanocomposite magnetic scaffolds for advanced bone tissue engineering," Journal of Applied Polymer Science, vol. 122, no. 6, pp. 3599-3605, 2011.

[31] X. Zhao, J. Kim, C. A. Cezar et al., "Active scaffolds for ondemand drug and cell delivery," Proceedings of the National Academy of Sciences of the United States of America, vol. 108, no. 1, pp. 67-72, 2011.

[32] D. Singh, J. M. McMillan, A. V. Kabanov, M. Sokolsky-Papkov, and H. E. Gendelman, "Bench-to-bedside translation of magnetic nanoparticles," Nanomedicine (Lond), vol. 9, no. 4, pp. 501-516, 2014.

[33] E. Delyagina, W. Li, N. Ma, and G. Steinhoff, "Magnetic targeting strategies in gene delivery," Nanomedicine (Lond), vol. 6, no. 9, pp. 1593-1604, 2011.

[34] H. Hamidian and T. Tavakoli, "Preparation of a new $\mathrm{Fe}_{3} \mathrm{O}_{4} / \mathrm{s}-$ tarch- $g$-polyester nanocomposite hydrogel and a study on swelling and drug delivery properties," Carbohydrate Polymers, vol. 144, pp. 140-148, 2016.

[35] Q. Chen, D. Liu, C. Wu et al., "Co-immobilization of cellulase and lysozyme on amino-functionalized magnetic nanoparticles: an activity-tunable biocatalyst for extraction of lipids from microalgae," Bioresource Technology, vol. 263, pp. 317-324, 2018.

[36] J. Wu, X. Cheng, and G. Yang, "Preparation of nanochitincontained magnetic chitosan microfibers via continuous injection gelation method for removal of $\mathrm{Ni}(\mathrm{II})$ ion from aqueous solution," International Journal of Biological Macromolecules, vol. 125, pp. 404-413, 2019.

[37] X. Xue, R. Lu, M. Liu, Y. Li, J. Li, and L. Wang, "A facile and general approach for the preparation of boronic acid-functionalized magnetic nanoparticles for the selective enrichment of glycoproteins," Analyst, vol. 144, no. 2, pp. 641-648, 2019.

[38] C. Yu, J. Geng, Y. Zhuang et al., "Preparation of the chitosan grafted poly (quaternary ammonium) $/ \mathrm{Fe}_{3} \mathrm{O}_{4}$ nanoparticles and its adsorption performance for food yellow 3," Carbohydrate Polymers, vol. 152, pp. 327-336, 2016.

[39] J. Huang, W. Liu, Y. Liang et al., "Preparation and biocompatibility of diphasic magnetic nanocomposite scaffold," Materials Science \& Engineering. C, Materials for Biological Applications, vol. 87, pp. 70-77, 2018.

[40] A. Maleki, "One-pot multicomponent synthesis of diazepine derivatives using terminal alkynes in the presence of silicasupported superparamagnetic iron oxide nanoparticles," Tetrahedron Letters, vol. 54, no. 16, pp. 2055-2059, 2013.

[41] A. Maleki, "One-pot three-component synthesis of pyrido $\left[2^{\prime}, 1^{\prime}\right.$ :2,3] imidazo[4,5-c] isoquinolines using $\mathrm{Fe}_{3} \mathrm{O}_{4} @ \mathrm{SiO}_{2}-\mathrm{OSO}_{3} \mathrm{H}$ as an efficient heterogeneous nanocatalyst," RSC Advances, vol. 4, no. 109, pp. 64169-64173, 2014.

[42] A. Maleki, "Green oxidation protocol: selective conversions of alcohols and alkenes to aldehydes, ketones and epoxides by using a new multiwall carbon nanotube-based hybrid nanocatalyst via ultrasound irradiation," Ultrasonics Sonochemistry, vol. 40, Part A, pp. 460-464, 2018.

[43] H. Gan and H. Xu, "A novel aptamer-based online magnetic solid phase extraction method for simultaneous determination of urinary 8-hydroxy-2'-deoxyguanosine and monohydroxylated polycyclic aromatic hydrocarbons," Talanta, vol. 201, pp. 271-279, 2019.

[44] K. Pandi, N. Viswanathan, and S. Meenakshi, "Hydrothermal synthesis of magnetic iron oxide encrusted hydrocalumitechitosan composite for defluoridation studies," International Journal of Biological Macromolecules, vol. 132, pp. 600-605, 2019.

[45] H. Saygili, "Hydrothermal synthesis of magnetic nanocomposite from biowaste matrix by a green and one-step route: Characterization and pollutant removal ability," Bioresource Technology, vol. 278, pp. 242-247, 2019.

[46] Y. Liu, T. Cui, T. Wu, Y. Li, and G. Tong, "Excellent microwave-absorbing properties of elliptical $\mathrm{Fe}_{2} \mathrm{O}_{2}$ nanorings made by a rapid microwave-assisted hydrothermal approach," Nanotechnology, vol. 27, no. 16, p. 165707, 2016.

[47] X. Wang, P. Y. Gao, Y. Y. Yang, H. Guo, and D. Wu, "Dynamic and programmable morphology and size evolution via a living hierarchical self-assembly strategy," Nature Communications, vol. 9, no. 1, p. 2772, 2018.

[48] C. Wan and J. Li, "Synthesis of well-dispersed magnetic $\mathrm{CoFe}_{2} \mathrm{O}_{4}$ nanoparticles in cellulose aerogels via a facile 
oxidative co-precipitation method," Carbohydrate Polymers, vol. 134, pp. 144-150, 2015.

[49] H. Nosrati, M. Salehiabar, H. K. Manjili, H. Danafar, and S. Davaran, "Preparation of magnetic albumin nanoparticles via a simple and one-pot desolvation and co-precipitation method for medical and pharmaceutical applications," International Journal of Biological Macromolecules, vol. 108, pp. 909-915, 2018.

[50] M. S. A. Darwish, H. Kim, H. Lee, C. Ryu, J. Y. Lee, and J. Yoon, "Synthesis of magnetic ferrite nanoparticles with high hyperthermia performance via a controlled coprecipitation method," Nanomaterials, vol. 9, no. 8, p. 1176, 2019.

[51] S. Majidi, F. Zeinali Sehrig, S. M. Farkhani, M. Soleymani Goloujeh, and A. Akbarzadeh, "Current methods for synthesis of magnetic nanoparticles," Artificial Cells, Nanomedicine, and Biotechnology, vol. 44, no. 2, pp. 722-734, 2016.

[52] W. Zhang, X. Li, R. Zou et al., "Multifunctional glucose biosensors from $\mathrm{Fe}_{3} \mathrm{O}_{4}$ nanoparticles modified chitosan/graphene nanocomposites," Scientific Reports, vol. 5, no. 1, p. 11129, 2015.

[53] Q. Yang, M. Zhou, M. Yang et al., "Highyield production of few-layer graphene via new-fashioned strategy combining resonance ball milling and hydrothermal exfoliation," Nanomaterials, vol. 10, no. 4, p. 667, 2020.

[54] V. Narayanaswamy, I. M. Obaidat, A. S. Kamzin et al., "Synthesis of graphene oxide- $\mathrm{Fe}_{3} \mathrm{O}_{4}$ based nanocomposites using the mechanochemical method and in vitro magnetic hyperthermia," International Journal of Molecular Sciences, vol. 20, no. 13, p. 3368, 2019.

[55] M. Amiri, K. Eskandari, and M. Salavati-Niasari, "Magnetically retrievable ferrite nanoparticles in the catalysis application," Advances in Colloid and Interface Science, vol. 271, p. 101982, 2019.

[56] H. M. Kayili and B. Salih, "Fast and efficient proteolysis by reusable pepsin-encapsulated magnetic sol- gel material for mass spectrometry-based proteomics applications," Talanta, vol. 155, pp. 78-86, 2016.

[57] J. Lin, J. Zhang, H. Sun et al., "Structural and magnetic property of $\mathrm{Cr} 3+$ substituted cobalt ferrite nanomaterials prepared by the sol-gel method," Materials, vol. 11, no. 11, p. 2095, 2018.

[58] J. Wang, Q. Zhang, X. Shao, J. Ma, and G. Tian, "Properties of magnetic carbon nanomaterials and application in removal organic dyes," Chemosphere, vol. 207, pp. 377-384, 2018.

[59] W. R. Bao, M. L. Li, Y. Y. Yang et al., "Advancements and frontiers in the high performance of natural hydrogels for cartilage tissue engineering," Frontiers in Chemistry, vol. 8, p. 53, 2020.

[60] L. Gao, Y. Tang, C. Wang et al., "Highly-efficient amphiphilic magnetic nanocomposites based on a simple sol-gel modification for adsorption of phthalate esters," Journal of Colloid and Interface Science, vol. 552, pp. 142-152, 2019.

[61] U. T. Sanli, C. Jiao, M. Baluktsian et al., "3D nanofabrication of high-resolution multilayer fresnel zone plates," Advanced Science, vol. 5, no. 9, article 1800346, 2018.

[62] Y. Li, T. Liang, R. Wang, B. He, Y. Gong, and H. Wang, "Encapsulation of $\mathrm{Fe}_{3} \mathrm{O}_{4}$ between copper nanorod and thin TiO2 film by ALD for lithium-ion capacitors," ACS Applied Materials \& Interfaces, vol. 11, no. 21, pp. 19115-19122, 2019.
[63] A. Ponti, M. H. Raza, F. Pantò et al., "Structure, defects, and magnetism of electrospun hematite nanofibers silica-coated by atomic layer deposition," Langmuir, vol. 36, no. 5, pp. 1305-1319, 2020.

[64] X. W. Bi, L. H. Li, Z. N. Mao et al., "The effects of silk layerby-layer surface modification on the mechanical and structural retention of extracellular matrix scaffolds," Biomaterials Science, vol. 8, no. 14, pp. 4026-4038, 2020.

[65] C. Y. Wang, B. Yu, Y. B. Fan et al., "Incorporation of multiwalled carbon nanotubes to PMMA bone cement improves cytocompatibility and osseointegration," Materials Science and Engineering: C, vol. 103, p. 109823, 2019.

[66] Q. Chen, C. Zhu, and G. A. Thouas, "Progress and challenges in biomaterials used for bone tissue engineering: bioactive glasses and elastomeric composites," Progress in Biomaterials, vol. 1, no. 1, p. 2, 2012.

[67] G. Wang, N. Z. Mostafa, V. Incani, C. Kucharski, and H. Uludağ, "Bisphosphonate-decorated lipid nanoparticles designed as drug carriers for bone diseases," Journal of Biomedial Materials Research Part A, vol. 100, pp. 684-693, 2012.

[68] G. Zhang, B. Guo, H. Wu et al., "A delivery system targeting bone formation surfaces to facilitate RNAi-based anabolic therapy," Nature Medicine, vol. 18, no. 2, pp. 307-314, 2012.

[69] J. Liu, H. Zhang, Y. Dong et al., "Bi-directionally selective bone targeting delivery for anabolic and antiresorptive drugs: a novel combined therapy for osteoporosis?," Medical Hypotheses, vol. 83, no. 6, pp. 694-696, 2014.

[70] S. Hirsjärvi, L. Sancey, S. Dufort et al., "Effect of particle size on the biodistribution of lipid nanocapsules: comparison between nuclear and fluorescence imaging and counting," International Journal of Pharmaceutics, vol. 453, no. 2, pp. 594-600, 2013.

[71] M. Nahar, T. Dutta, S. Murugesan et al., "Functional polymeric nanoparticles: an efficient and promising tool for active delivery of bioactives," Critical Reviews in Therapeutic Drug Carrier Systems, vol. 23, no. 4, pp. 259-318, 2006.

[72] S. Y. An, M.-P. N. Bui, Y. J. Nam et al., "Preparation of monodisperse and size-controlled poly(ethylene glycol) hydrogel nanoparticles using liposome templates," Journal of Colloid and Interface Science, vol. 331, no. 1, pp. 98-103, 2009.

[73] N. Monteiro, A. Martins, R. L. Reis, and N. M. Neves, "Liposomes in tissue engineering and regenerative medicine," Journal of the Royal Society Interface, vol. 11, pp. 281-297, 2014.

[74] R. Qi, I. Majoros, A. C. Misra et al., "Folate receptor-targeted dendrimer-methotrexate conjugate for inflammatory arthritis," Journal of Biomedical Nanotechnology, vol. 11, pp. 13701384, 2014.

[75] R. Duncan and L. Izzo, "Dendrimer biocompatibility and toxicity," Advanced Drug Delivery Reviews, vol. 57, no. 15, pp. 2215-2237, 2005.

[76] B. De la Riva, E. Sánchez, A. Hernández et al., "Local controlled release of VEGF and PDGF from a combined brushite-chitosan system enhances bone regeneration," Journal of Controlled Release, vol. 143, no. 1, pp. 45-52, 2010.

[77] A. Rampino, M. Borgogna, P. Blasi, B. Bellich, and A. Cesàro, "Chitosan nanoparticles: preparation, size evolution and stability," International Journal of Pharmaceutics, vol. 455, no. 1-2, pp. 219-228, 2013.

[78] W. S. Vedakumari, P. Prabu, and T. P. Sastry, "Chitosanfibrin nanocomposites as drug delivering and wound healing 
materials," Journal of Biomedical Nanotechnology, vol. 11, no. 4, pp. 657-667, 2015.

[79] I. K. Shim, W. H. Suh, S. Y. Lee et al., "Chitosan nano-/microfibrous double-layered membrane with rolled-up threedimensional structures for chondrocyte cultivation," Journal of Biomedial Materials Research Part A, vol. 90, pp. 595602, 2009.

[80] N. Poth, V. Seiffart, G. Gross, H. Menzel, and W. Dempwolf, "Biodegradable chitosan nanoparticle coatings on titanium for the delivery of BMP-2," Biomolecules, vol. 5, no. 1, pp. 3-19, 2015.

[81] U. Nagarajan, K. Kawakami, and S. Zhang, "Fabrication of solid collagen nanoparticles using electrospray deposition," Pharmaceutical Bulletin, vol. 62, no. 5, pp. 422-428, 2014.

[82] Y. Liu, Y. Lu, X. Tian et al., "Segmental bone regeneration using an rhBMP-2-loaded gelatin/nanohydroxyapatite/fibrin scaffold in a rabbit model," Biomaterials, vol. 30, no. 31, pp. 6276-6285, 2009.

[83] M. Jahanshahi, M. H. Sanati, S. Hajizadeh, and Z. Babaei, "Gelatin nanoparticle fabrication and optimization of the particle size," Physica Status Solidi (a), vol. 205, no. 12, pp. 2898-2902, 2008.

[84] D. C. Miller, A. Thapa, K. M. Haberstroh, and T. J. Webster, "Endothelial and vascular smooth muscle cell function on poly(lactic-co- glycolic acid) with nano-structured surface features," Biomaterials, vol. 25, no. 1, pp. 53-61, 2004.

[85] F. Danhier, E. Ansorena, J. M. Silva, R. Coco, A. le Breton, and V. Préat, "PLGA-based nanoparticles: an overview of biomedical applications," Journal of Controlled Release, vol. 161, no. 2, pp. 505-522, 2012.

[86] M. A. Pattison, S. Wurster, T. J. Webster, and K. M. Haberstroh, "Three-dimensional, nano-structured PLGA scaffolds for bladder tissue replacement applications," Biomaterials, vol. 26, no. 15, pp. 2491-2500, 2005.

[87] C. Soundrapandian, A. Mahato, B. Kundu, S. Datta, B. Sa, and D. Basu, "Development and effect of different bioactive silicate glass scaffolds: in vitro evaluation for use as a bone drug delivery system," Journal of the Mechanical Behavior of Biomedical Materials, vol. 40, pp. 1-12, 2014.

[88] M. Baldrighi, M. Trusel, and R. Tonini, "Carbon nanomaterials interfacing with neurons: an in vivo perspective," Frontiers in Neuroscience, vol. 10, p. 250, 2016.

[89] B. Gorain, H. Choudhury, M. Pandey et al., "Carbon nanotube scaffolds as emerging nanoplatform for myocardial tissue regeneration: a review of recent developments and therapeutic implications," Biomedicine \& Pharmacotherapy, vol. 104, pp. 496-508, 2018.

[90] Z. Zhu, "An overview of carbon nanotubes and graphene for biosensing applications," Nano-Micro Letters, vol. 9, no. 3, p. 25, 2017.

[91] L. Wang, C. Y. Wang, S. Wu, Y. Fan, and X. Li, "Influence of the mechanical properties of biomaterials on degradability, cell behaviors and signaling pathways: current progress and challenges," Biomaterials Science, vol. 8, no. 10, pp. 27142733, 2020.

[92] N. Bock, A. Riminucci, C. Dionigi et al., "A novel route in bone tissue engineering: magnetic biomimetic scaffolds," Acta Biomaterialia, vol. 6, no. 3, pp. 786-796, 2010.

[93] N. A. Usov, S. A. Gudoshnikov, N. Serebryakova, M. L. FdezGubieda, A. Muela, and J. M. Barandiarán, "Properties of dense assemblies of magnetic nanoparticles promising for application in biomedicine," Journal of Superconductivity and Novel Magnetism, vol. 26, no. 4, pp. 1079-1083, 2013.

[94] E. Akaraonye, J. Filip, M. Safarikova et al., "Composite scaffolds for cartilage tissue engineering based on natural polymers of bacterial origin, thermoplastic poly(3-hydroxybutyrate) and micro-fibrillated bacterial cellulose," Polymer International, vol. 65, no. 7, pp. 780-791, 2016.

[95] A. Bhowmick, P. Jana, N. Pramanik et al., "Multifunctional zirconium oxide doped chitosan based hybrid nanocomposites as bone tissue engineering materials," Carbohydrate Polymers, vol. 151, pp. 879-888, 2016.

[96] S. Aliramaji, A. Zamanian, and M. Mozafari, "Super-paramagnetic responsive silk fibroin/chitosan/magnetite scaffolds with tunable pore structures for bone tissue engineering applications," Materials Science and Engineering: C, vol. 70, Part 1, pp. 736-744, 2017.

[97] J. H. Huang, J. Y. Xiong, D. P. Wang et al., "Performance of magnetic nanocomposite artificial bone scaffolds prepared by low-temperature rapid prototyping 3D printing," Hainan Medical Journal (Hai Nan Yi Xue), vol. 6, no. 7, pp. 678-687, 2017.

[98] J. Meng, B. Xiao, Y. Zhang et al., "Super-paramagnetic responsive nanofibrous scaffolds under static magnetic field enhance osteogenesis for bone repair in vivo," Scientific Reports, vol. 3, no. 1, article 2655, 2013.

[99] R. K. Singh, K. D. Patel, J. H. Lee et al., "Potential of magnetic nanofiber scaffolds with mechanical and biological properties applicable for bone regeneration," PloS One, vol. 9, no. 4, article e91584, 2014.

[100] Y. J. Li, H. Chen, J. Wu et al., "Preparation and characterization of APTES modified magnetic MMT capable of using as anisotropic nanoparticles," Applied Surface Science, vol. 447, pp. 393-400, 2018.

[101] S. C. Zhao, M. Zhu, J. H. Zhang et al., "Three dimensionally printed mesoporous bioactive glass and poly(3-hydroxybutyrate-co-3-hydroxyhexanoate) composite scaffolds for bone regeneration," Journal of Materials Chemistry, B, vol. 2, no. 36, pp. 6106-6118, 2014.

[102] Z. du, X. X. Feng, G. X. Cao et al., "The effect of carbon nanotubes on osteogenic functions of adipose-derived mesenchymal stem cells_in vitro_ and bone formation _in vivo_ compared with that of nano-hydroxyapatite and the possible mechanism," Bioactive Materials, vol. 6, no. 2, pp. 333-345, 2021.

[103] C. Shuai, P. Feng, P. Wu et al., "A combined nanostructure constructed by graphene and boron nitride nanotubes reinforces ceramic scaffolds," Chemical Engineering Journal, vol. 313, pp. 487-497, 2017.

[104] K. Wójcik-Piotrowicz, J. Kaszuba-Zwoińska, E. Rokita, and P. Thor, "Cell viability modulation through changes of $\mathrm{Ca}^{2+}$-dependent signalling pathways," Progress in Biophysics and Molecular Biology, vol. 121, no. 1, pp. 45-53, 2016.

[105] Y. Zhu, Q. Yang, M. Yang et al., "Protein corona of magnetic hydroxyapatite scaffold improves cell proliferation via activation of mitogen-activated protein kinase signaling pathway," ACS Nano, vol. 11, no. 4, pp. 3690-3704, 2017.

[106] E. Díaz, M. B. Valle, S. Ribeiro, S. Lanceros-Mendez, and J. Barandiarán, "Development of magnetically active scaffolds for bone regeneration," Nanomaterials, vol. 8, no. 9, p. 678, 2018.

[107] J. Wang, Y. An, F. Li et al., "The effects of pulsed electromagnetic field on the functions of osteoblasts on implant surfaces 
with different topographies," Acta Biomaterialia, vol. 10, no. 2, pp. 975-985, 2014.

[108] A. Tampieri, S. Sprio, M. Sandri, and F. Valentini, "Mimicking natural bio-mineralization processes: a new tool for osteochondral scaffold development," Trends in Biotechnology, vol. 29, no. 10, pp. 526-535, 2011.

[109] M. Arjmand, A. Ardeshirylajimi, H. Maghsoudi, and E. Azadian, "Osteogenic differentiation potential of mesenchymal stem cells cultured on nanofibrous scaffold improved in the presence of pulsed electromagnetic field," Journal of Cellular Physiology, vol. 233, 2017.

[110] J. W. Lu, F. Yang, Q. Ke, X. T. Xie, and Y. P. Guo, "Magnetic nanoparticles modified-porous scaffolds for bone regeneration and photothermal therapy against tumors," Nanomedicine, vol. 14, no. 3, pp. 811-822, 2018.

[111] M. Cruz-Acuña, J. R. Halman, K. A. Afonin, J. Dobson, and C. Rinaldi, "Magnetic nanoparticles loaded with functional RNA nanoparticles," Nanoscale, vol. 10, no. 37, pp. 1776117770, 2018.

[112] J. H. Kuai, Q. Wang, A. J. Zhang et al., "Epidermal growth factor receptor-targeted immune magnetic liposomes capture circulating colorectal tumor cells efficiently," World Journal of Gastroenterology, vol. 24, no. 3, pp. 351-359, 2018.

[113] C. Luo, X. Yang, M. Li et al., "A novel strategy forin vivoangiogenesis and osteogenesis: magnetic micromovement in a bone scaffold," Artificial Cells, Nanomedicine, and Biotechnology, vol. 46, Supplement 2, pp. 636-645, 2018.

[114] F. D. Cojocaru, V. Balan, M. I. Popa et al., "Biopolymers - calcium phosphates composites with inclusions of magnetic nanoparticles for bone tissue engineering," International Journal of Biological Macromolecules, vol. 125, pp. 612-620, 2019.

[115] Z. Y. Liu, J. H. Liu, X. Cui, X. Wang, L. Zhang, and P. Tang, "Recent advances on magnetic sensitive hydrogels in tissue engineering," Frontiers in Chemistry, vol. 8, p. 124, 2020.

[116] Z. F. Huang, Y. He, X. Chang et al., "A magnetic iron oxide/polydopamine coating can improve osteogenesis of 3DPrinted porous titanium scaffolds with a static magnetic field by upregulating the TGF $\beta$-Smads pathway," Advanced Healthcare Materials, vol. 9, no. 14, p. 2000318, 2020.

[117] C. Shuai, W. Yang, C. He et al., "A magnetic microenvironment in scaffolds for stimulating bone regeneration," Materials \& Design, vol. 185, article 108275, 2019.

[118] Y. Xia, Y. Guo, Z. Yang et al., "Iron oxide nanoparticlecalcium phosphate cement enhanced the osteogenic activities of stem cells through WNT/ $\beta$-catenin signalling - ScienceDirect," Materials Science and Engineering: C, vol. 104, 2019.

[119] A. S. Saraiva, I. A. C. Ribeiro, M. H. Fernandes et al., "3D-printed platform multi-loaded with bioactive, magnetic nanoparticles and an antibiotic for re-growing bone tissue," International Journal of Pharmaceutics X, vol. 593, pp. 120097-120097, 2020.

[120] H.-Y. Lin, H.-Y. Huang, S.-J. Shiue, and J.-K. Cheng, "Osteogenic effects of inductive coupling magnetism from magnetic 3D printed hydrogel scaffold," Journal of Magnetism and Magnetic Materials, vol. 504, 2020.

[121] F. Ghorbani, A. Zamanian, A. Shams, A. Shamoosi, and A. Aidun, "Fabrication and characterisation of super-paramagnetic responsive PLGA-gelatine-magnetite scaffolds with the unidirectional porous structure: a physicochemical, mechanical, andin vitroevaluation," IET Nanobiotechnology, vol. 13, no. 8, pp. 860-867, 2019.
[122] J. J. Kim, R. K. Singh, S. J. Seo et al., "Magnetic scaffolds of polycaprolactone with functionalized magnetite nanoparticles: physicochemical, mechanical, and biological properties effective for bone regeneration," RSC Advances, vol. 4, no. 33, pp. 17325-17336, 2014.

[123] H. Wang, S. Zhao, J. Zhou et al., "Biocompatibility and osteogenic capacity of borosilicate bioactive glass scaffolds loaded with Fe3O4magnetic nanoparticles," Journal of Materials Chemistry B, vol. 3, no. 21, article 4377, 4387 pages, 2015.

[124] Y. Watanabe, N. Harada, K. Sato, S. Abe, K. Yamanaka, and T. Matushita, "Stem cell therapy: is there a future for reconstruction of large bone defect?," Injury, vol. 47, pp. S47-S51, 2016.

[125] M. Barrow, A. Taylor, P. Murray, M. J. Rosseinsky, and D. J. Adams, "Design considerations for the synthesis of polymer at iron oxide nanoparticles for stem labelling and tracking using MRI," Chemical Society Reviews, vol. 44, no. 19, pp. 6733-6748, 2015.

[126] Y. Jia, P. Zhang, Y. Sun et al., "Regeneration of large bone defects using mesoporous silica coated magnetic nanoparticles during distraction osteogenesis," Nanomedicine: Nanotechnology, Biology and Medicine, vol. 21, article 102040, 2019.

[127] W. Yang, P. Zhu, H. Huang et al., "Functionalization of novel theranostic hydrogels with kartogenin-grafted USPIO nanoparticles to enhance cartilage regeneration," ACS Applied Materials \& Interfaces, vol. 11, no. 38, pp. 34744-34754, 2019.

[128] C. Xu, S. Wang, L. Liu, S. Yu, X. Wu, and H. Dai, "Manipulating mesenchymal stem cells differentiation under sinusoidal electromagnetic fields using intracellular superparamagnetic nanoparticles," Journal of Biomedical Nanotechnology, vol. 15, no. 2, pp. 301-310, 2019.

[129] M. Tatullo, M. Marrelli, K. M. Shakesheff, and L. J. White, "Dental pulp stem cells: function, isolation and applications in regenerative medicine," Journal of Tissue Engineering and Regenerative Medicine, vol. 9, no. 11, pp. 1205-1216, 2015.

[130] B. Lindroos, K. Mäenpää, T. Ylikomi, H. Oja, R. Suuronen, and S. Miettinen, "Characterisation of human dental stem cells and buccal mucosa fibroblasts," Biochemical and Biophysical Research Communications, vol. 368, no. 2, pp. 329335, 2008.

[131] R. d'Aquino, A. Graziano, M. Sampaolesi et al., "Human postnatal dental pulp cells co-differentiate into osteoblasts and endotheliocytes: a pivotal synergy leading to adult bone tissue formation," Cell Death and Differentiation, vol. 14, no. 6, pp. 1162-1171, 2007.

[132] R. d'Aquino, G. Papaccio, G. Laino, and A. Graziano, "Dental pulp stem cells: a promising tool for bone regeneration," Stem Cell Reviews, vol. 4, no. 1, pp. 21-26, 2008.

[133] Q. Wang, B. Chen, F. Ma et al., "Magnetic iron oxide nanoparticles accelerate osteogenic differentiation of mesenchymal stem cells via modulation of long noncoding RNA INZEB2," Nano Research, vol. 10, no. 2, pp. 626-642, 2017.

[134] A. H. Silva, E. Lima, M. V. Mansilla et al., "Superparamagnetic iron-oxide nanoparticles mPEG350- and mPEG2000-coated: cell uptake and biocompatibility evaluation," Nanomedicine, vol. 12, no. 4, pp. 909-919, 2016.

[135] P. Hua, Y. Y. Wang, L. B. Liu et al., "In vivo magnetic resonance imaging tracking of transplanted superparamagnetic iron oxide-labeled bone marrow mesenchymal stem cells in 
rats with myocardial infarction," Molecular Medicine Reports, vol. 11, no. 1, pp. 113-120, 2015.

[136] L. H. A. Silva, M. C. Silva, J. B. Vieira et al., "Magnetic targeting increases mesenchymal stromal cell retention in lungs and enhances beneficial effects on pulmonary damage in experimental silicosis," Stem Cells Translational Medicine, vol. 9, no. 10, pp. 1244-1256, 2020.

[137] R. Shelat, L. K. Bhatt, B. Paunipagar, T. Kurian, A. Khanna, and S. Chandra, "Regeneration of hyaline cartilage in osteochondral lesion model using L-lysine magnetic nanoparticles labeled mesenchymal stem cells and their In Vivo imaging," Journal of Tissue Engineering and Regenerative Medicine, vol. 14, no. 11, pp. 1604-1617, 2020.

[138] D. Yao, N. N. Liu, and B. W. Mo, "Assessment of proliferation, migration and differentiation potentials of bone marrow mesenchymal stem cells labeling with silica-coated and amine-modified superparamagnetic iron oxide nanoparticles," Cytotechnology, vol. 72, no. 4, pp. 513-525, 2020.

[139] A. B. Mathiasen, A. A. Qayyum, E. Jørgensen et al., "In vivo MRI tracking of mesenchymal stromal cells labeled with ultrasmall paramagnetic iron oxide particles after intramyocardial transplantation in patients with chronic ischemic heart disease," Stem Cells International, vol. 2019, Article ID 2754927, 10 pages, 2019.

[140] R. Jiang, Y. Liao, F. Yang, Y. Cheng, X. Dai, and J. Chao, "SPIO nanoparticle-labeled bone marrow mesenchymal stem cells inhibit pulmonary EndoMT induced by $\mathrm{SiO}_{2}$," Experimental Cell Research, vol. 383, no. 1, p. 111492, 2019.

[141] A. Nel, T. Xia, L. Mädler, and N. Li, "Toxic potential of materials at the nanolevel," Science, vol. 311, no. 5761, pp. 622$627,2006$.

[142] U. O. Häfeli, J. S. Riffle, L. Harris-Shekhawat et al., "Cell uptake and in vitro toxicity of magnetic nanoparticles suitable for drug delivery," Molecular Pharmaceutics, vol. 6, no. 5, pp. 1417-1428, 2009.

[143] G. Oberdorster, V. Stone, and K. Donaldson, "Toxicology of nanoparticles: a historical perspective," Nanotoxicology, vol. 1, no. 1, pp. 2-25, 2007.

[144] P. Møller, N. R. Jacobsen, J. K. Folkmann et al., "Role of oxidative damage in toxicity of particulates," Free Radical Research Communications, vol. 44, no. 1, pp. 1-46, 2010.

[145] K. Unfried, C. Albrecht, L.-O. Klotz, A. Von Mikecz, S. Grether-Beck, and R. P. F. Schins, "Cellular responses to nanoparticles: target structures and mechanisms," Nanotoxicology, vol. 10, no. 6, pp. 52-71, 2007.

[146] A. Elias, "Imaging circulating cells and lymphoid tissues with iron oxide nanoparticles," Hematology, vol. 2009, no. 1, pp. 720-726, 2009.

[147] B. Ankamwar, T. C. Lai, J. H. Huang et al., "Biocompatibility of $\mathrm{Fe} 3 \mathrm{O} 4$ nanoparticles evaluated byin vitrocytotoxicity assays using normal, glia and breast cancer cells," Nanotechnology, vol. 21, no. 7, p. 075102, 2010.

[148] J. Bulte, T. Douglas, B. Witwer et al., "Magnetodendrimers allow endosomal magnetic labeling and_in vivo_ tracking of stem cells," Nature Biotechnology, vol. 19, no. 12, pp. 1141-1147, 2001.

[149] J. M. Veranth, E. G. Kaser, M. M. Veranth, M. Koch, and G. S. Yost, "Cytokine responses of human lung cells (BEAS-2B) treated with micron-sized and nanoparticles of metal oxides compared to soil dusts," Particle and Fibre Toxicology, vol. 4, no. 1, pp. 1-18, 2007.
[150] N. Singh, "Conference scene - nanotoxicology: health and environmental impacts," Nanomedicine, vol. 4, no. 4, pp. 385-390, 2009.

[151] Z. G. M. Lacava, R. B. Azevedo, L. M. Lacava et al., “Toxic effects of ionic magnetic fluids in mice," Journal of Magnetism and Magnetic Materials, vol. 194, no. 1-3, pp. 90-95, 1999.

[152] J. Xie, G. Liu, H. S. Eden, H. Ai, and X. Chen, "Surface-engineered magnetic nanoparticle platforms for cancer imaging and therapy," Accounts of Chemical Research, vol. 44, no. 10, pp. 883-892, 2011.

[153] C. C. Berry, S. Wells, S. Charles, and A. S. G. Curtis, "Dextran and albumin derivatised iron oxide nanoparticles: influence on fibroblasts in vitro," Biomaterials, vol. 24, no. 25, pp. 4551-4557, 2003.

[154] C. C. Berry, S. Wells, S. Charles, G. Aitchison, and A. S. G. Curtis, "Cell response to dextran-derivatised iron oxide nanoparticles post internalisation," Biomaterials, vol. 25, no. 23, pp. 5405-5413, 2004.

[155] A. Hanini, A. Schmitt, K. Kacem, F. Chau, S. Ammar, and J. Gavard, "Evaluation of iron oxide nanoparticle biocompatibility," International Journal of Nanomedicine, vol. 6, pp. 787-794, 2011.

[156] J. Curtis, M. Greenberg, J. Kester, S. Phillips, and G. Krieger, "Nanotechnology and nanotoxicology," Toxicological Reviews, vol. 25, no. 4, pp. 245-260, 2006.

[157] S. M. Moghimi, A. C. Hunter, and J. C. Murray, "Nanomedicine: current status and future prospects," Faseb Journal, vol. 19, no. 3, pp. 311-330, 2005.

[158] R. Weissleder, D. D. Stark, B. L. Engelstad et al., "Superparamagnetic iron oxide: pharmacokinetics and toxicity," American Journal of Roentgenology, vol. 152, no. 1, pp. 167-173, 1989. 